\title{
A common set of developmental miRNAs are upregulated in Nicotiana benthamiana by diverse begomoviruses
}

\author{
Imran Amin ${ }^{1,2}$, Basavaprabhu L Patil ${ }^{2}$, Rob W Briddon', Shahid Mansoor ${ }^{1 *}$ and Claude M Fauquet $^{2}$
}

\begin{abstract}
Background: Begomoviruses are single-stranded DNA viruses that cause economically important diseases of many crops throughout the world and induce symptoms in plants, including enations, leaf curling and stunting, that resemble developmental abnormalities. MicroRNAs (miRNAs) are small endogenous RNAs that are involved in a variety of activities, including plant development, signal transduction and protein degradation, as well as response to environmental stress, and pathogen invasion.

Results: The present study was aimed at understanding the deregulation of miRNAs upon begomovirus infection. Four distinct begomoviruses African cassava mosaic virus (ACMV), Cabbage leaf curl virus (CbLCUV), Tomato yellow leaf curl virus (TYLCV) and Cotton leaf curl Multan virus/Cotton leaf curl betasatellite (CLCUV/CLCUMB), were used in this study. Ten developmental miRNA were studied. N. benthamiana plants were inoculated with begomoviruses and their miRNA profiles were analysed by northern blotting using specific miRNA probes. The levels of most developmental miRNA were increased in N. benthamiana by TYLCV, CLCUMV/CLCUMB and CbLCuV infection with a common pattern despite their diverse genomic components. However, the increased levels of individual miRNAs differed for distinct begomoviruses, reflecting differences in severity of symptom phenotypes. Some of these miRNA were also common to ACMV infection.

Conclusions: Our results have shown a common pattern of miRNAs accumulation upon begomovirus infection. It was found that begomoviruses generally increase the accumulation of miRNA and thus result in the decreased translation of genes involved in the development of plants. Identification of common miRNAs that are deregulated upon begomovirus infection may provide novel targets for control strategies aimed at developing broad-spectrum resistance.
\end{abstract}

\section{Background}

MicroRNAs (miRNAs) are endogenous, approx. $22 \mathrm{nt}$ RNAs that can play important regulatory roles in animals and plants by targeting mRNA for cleavage or translational repression [1]. miRNA are the second most abundant class of RNA among short RNAs [2] that play a very important role in multicellular organisms and influence the output of many protein-coding genes. The first miRNAs were discovered during a study of nematode larval development. Two approximately $22 \mathrm{nt}$

\footnotetext{
* Correspondence: shahidmansoor7@gmail.com

'Agricultural Biotechnology Division, National Institute for Biotechnology and Genetic Engineering (NIBGE), P O Box 577, Jhang Road, Faisalabad, Pakistan, ILTAB, Donald

Full list of author information is available at the end of the article
}

RNAs (the lin-4 and let-7 RNAs) control developmental timing by binding to their respective mRNA targets preventing their translation $[3,4]$.

In mid-2002, four groups reported RNAs with miRNA characteristics among the tiny RNAs present in Arabidopsis [5-8]. An important difference between plant and animal miRNAs is that the regulatory targets of plant miRNAs can be predicted with a fair degree of confidence, simply by identifying mRNAs with near perfect complementarity [9].

The discovery of miRNAs in plants is still an ongoing process. Much focus has been directed toward miRNA identification in Arabidopsis and rice, but many species which are important economically or evolutionarily have yet to be examined. Initial cloning of small RNAs from

\section{Biomed Central}

(c) 2011 Amin et al; licensee BioMed Central Ltd. This is an Open Access article distributed under the terms of the Creative Commons Attribution License (http://creativecommons.org/licenses/by/2.0), which permits unrestricted use, distribution, and reproduction in any medium, provided the original work is properly cited. 
Arabidopsis and rice has revealed that plants are extremely rich in endogenous small RNAs and that only a small portion of cloned small RNAs correspond to miRNAs $[6,10]$. The majority of endogenous small RNA species represent small interfering RNAs (siRNAs). The difference between miRNAs and siRNAs lies in their biogenesis. miRNAs originate from the processing of single-stranded precursors that form a hairpin structure, whereas siRNAs are generated from long doublestranded RNAs (dsRNAs) or single-stranded RNAs that form hairpin structures [6].

Plant miRNAs have a high degree of sequence complementarity to their target mRNAs and direct the slicing of the target mRNAs in the middle of the complementary regions $[10,11]$. This has been demonstrated by the detection of 3' cleavage products that have 5' ends that start in the middle of the complementary regions. This is probably mediated by AGO1 $[12,13]$. However, plant miRNAs also regulate gene expression by translational repression [14-17].

Geminiviruses are an important group of plant viruses with small circular, single-stranded (ss) DNA genomes that replicate in the nucleus of infected cells [18]. Viruses of the family Geminiviridae are divided into four genera based on insect vectors and genome organization [19]. Whitefly-transmitted geminiviruses are classified in the genus Begomovirus and constitute the largest genus that causes economically-important diseases throughout the warmer parts of the world [19-21]. Begomoviruses originating from the New World are invariably bipartite, with genomes consisting of two ssDNA components, known as DNA A and DNA B, of approximately equal size $(\sim 2.8 \mathrm{~kb})$. Although a few bipartite begomoviruses are known in the Old World, the vast majority of begomoviruses are monopartite with a genome that is a homolog of the DNA A component of the bipartite viruses, and most of these interact with ssDNA satellites [22]. Some begomoviruses, such as Tomato yellow leaf curl virus (TYLCV), are monopartite while a DNA satellite resembling betasatellite was found associated with Tomato leaf curl virus (ToLCV) [23].

Plant virus infections can result in disease symptoms that may include chlorosis and/or necrosis, curling, stunting and altered plant stature and morphology, presumably caused by interference of the infection with developmental processes [24]. In recent years, it has been proven experimentally that short RNA (sRNA), and particularly miRNAs, play important roles in plant development and are implicated in host-pathogen interactions $[25,26]$.

Recent studies in plants and animals suggest that viruses can suppress gene expression and use endogenous RNA-silencing pathways to regulate host gene expression, presumably to benefit virus replication
[26-29]. However, the underlying mechanisms that control these activities remain unclear. Epstein-Barr virus and other DNA viruses encode miRNAs that directly down- or up-regulate host and/or viral mRNAs [28].

Several studies have demonstrated that viral suppressors of RNA silencing can interfere with miRNAmediated regulation of host genes [30,31]. These studies showed that viral proteins interfere with miRNA pathways, although it is unclear whether it is part of the virus replication strategy or a side effect due to the overlap of the siRNA and miRNA pathways.

Transgenic expression in plants of the $\mathrm{AC} 4$ protein from ACMV, a suppressor of post-transcriptional gene silencing (PTGS) [32], was correlated with decreased accumulation of host miRNAs and increased development abnormalities in Arabidopsis thaliana [33]. Down- regulation of miRNA correlated with an up-regulation of target mRNA level. Another study showed that infection of $N$. tabacum by plant RNA viruses representative of the Tobamoviridae, Potyviridae, and Potexviridae families altered accumulation of certain miRNAs [34].

In the present study the accumulation of ten miRNAs were studied as a result of the infection of four viruses belonging to different types of begomovirus. African cassava mosaic virus (ACMV; representing a bipartite virus from the Old World), Cabbage leaf curl virus (CbLCuV: representing a bipartite virus from New World), Tomato yellow leaf curl virus (TYLCV; representing a monopartite virus) and Cotton leaf curl Multan virus/cotton leaf curl Multan betasatellite (CLCuMV/CLCuMB: representing a betasatellite requiring monopartite virus) were used in this study. The accumulation of miRNA as a result of the infection of each virus was then compared to assess the possible role of specific miRNAs in virus pathogenicity.

\section{Results}

\section{Virus infection}

Potato virus $X$ (PVX) infection of $N$. benthamiana resulted in mild symptoms including mild vein yellowing, very mild vein thickening and a faint mosaic that appeared approx. $10 \mathrm{dpi}$. Additionally, at approx. $15 \mathrm{dpi}$, $N$. benthamiana plants infected with PVX ceased to show symptoms, indicative of recovery (Figure 1 panel B). Infection of CLCuMV/CLCuMB resulted in downward leaf curling, vein yellowing, stunting, vein swelling, and the formation of small enations on the veins on the undersides of leaves (Figure 1 panels $C$ and D). $N$. benthamiana plants infected with $\mathrm{CbLCuV}$ showed mild symptoms after $16 \mathrm{dpi}$ that include mild leaf curling and deformed leaves at the margins (Figure 1 panel G). TYLCV infection in N. benthamiana resulted in a stunted growth, severe downward leaf curling and vein 

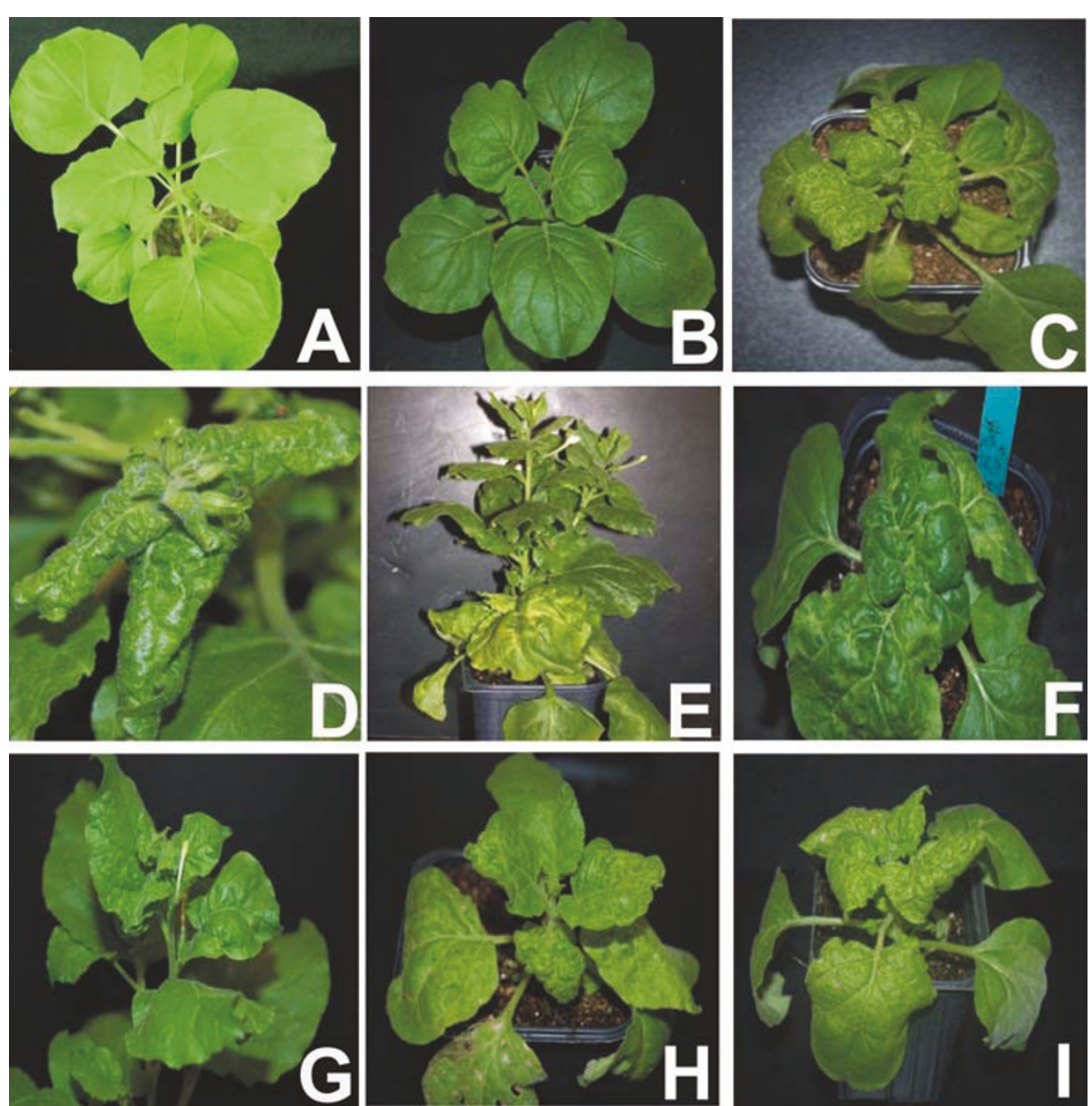

Figure 1 Photographs of a healthy $N$. benthamiana plant (panel A), and $N$. benthamiana plants infected with PVX (panel B), CLCUMV/CLCuMB (panels C and D), ACMV (panels E and F) CbLCuV (panel G) and TYLCV (panels H and I). Photographs were taken at approx. $21 \mathrm{dpi}$.

yellowing (Figure 1 panels $\mathrm{H}$ and I). The presence of each virus was confirmed by PCR using specific primers designed to the replication-associated gene of each virus (data not shown).

\section{Effects of virus infection on miR156 levels}

Upon infection of $N$. benthamiana by ACMV and CbLCuV the level of miR156 decreases as compared to $N$. benthamiana while the infection of TYLCV and CLCuMV resulted in an increased accumulation of miR156 (Figure 2). PVX infection, which was used in this study as a control and a representative RNA virus, resulted in an increased accumulation of miR156 when compared with un-inoculated $N$. benthamiana plant (Figure 2).

\section{- miR159}

Infections of all begomoviruses under study resulted in an increase in the accumulation of miR159 when compared with healthy $N$. benthamiana plants. The highest increase was observed in case of the infection of
CbLCuV (Figure 2). PVX infection also resulted in elevated level of miR159 as compared to healthy control (Figure 2).

\section{- $\operatorname{miR} 160$}

Infections of CbLCuV, TYLCV and CLCuMV resulted in a slight increase while ACMV resulted in decrease in the levels of miR160 when compared with healthy control plants (Figure 2). PVX infection also resulted in a slight decrease in the level of miR160 (Figure 2).

\section{-miR164}

$N$. benthamiana plants infected with ACMV, CLCuMV, $\mathrm{CbLCuV}$ and TYLCV showed an increase in the level of miR164 when compared with un-inoculated healthy plant. A maximum increase was observed in the infection of $\mathrm{CbLCuV}$ (Figure 2). Infection of PVX also resulted in an increase accumulation of miR164 (Figure 2).

\section{-miR165 and miR166}

Infection of $N$. benthamiana plants with ACMV, CLCuMV, CbLCuV and TYLCV resulted in an increase 


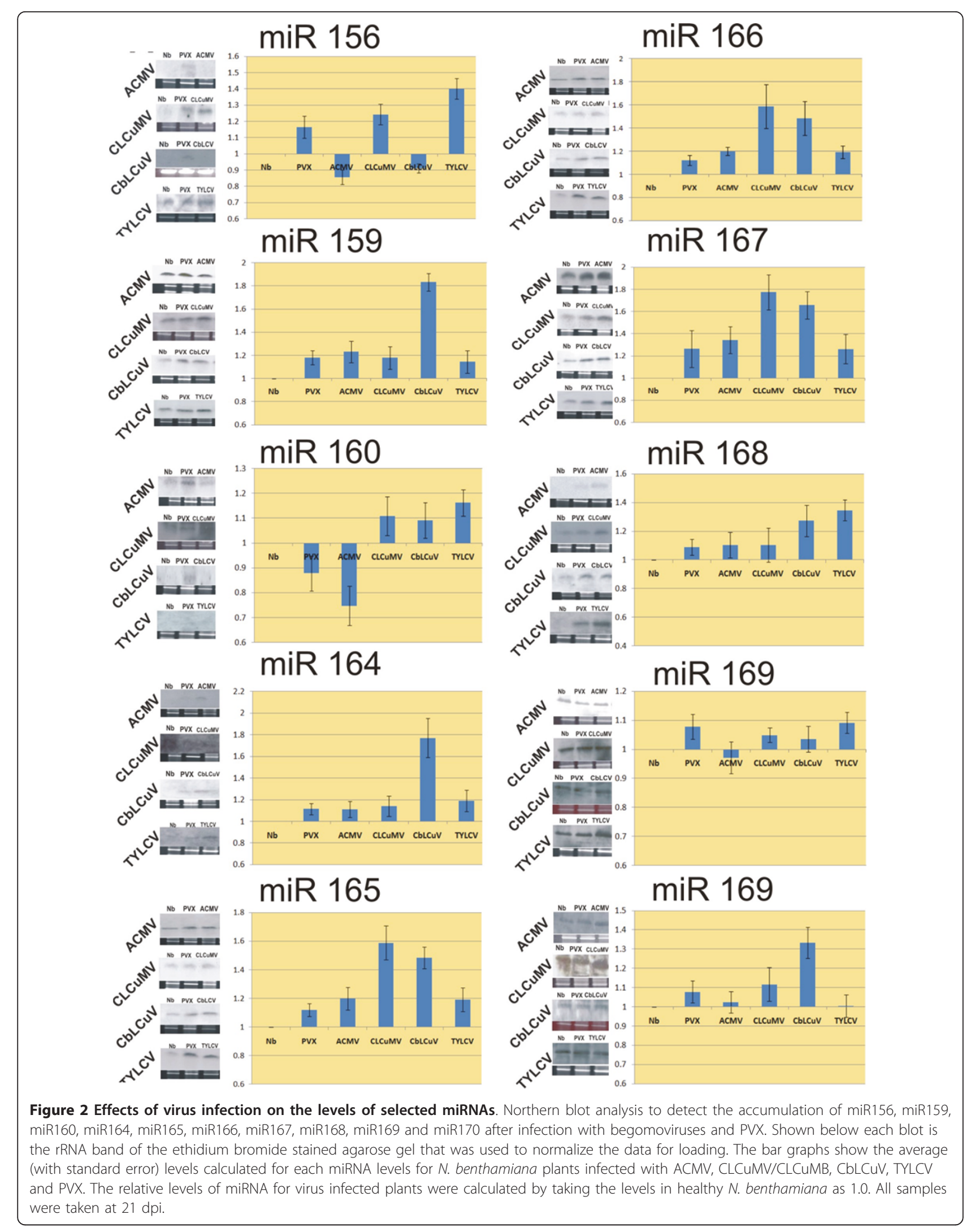


in the accumulation of miR165/166 when compared with the healthy control plants. The highest increase was observed in plants infected with CLCuMV (Figure 2). Infection of PVX also resulted in an increase in the accumulation of miR165/166 when compared with healthy $N$. benthamiana plants (Figure 2). However, this increase in accumulation of miR165/166 was less than for the begomovirus infection.

\section{-miRNA 167}

Infection with ACMV, CLCuMV, CbLCuV and TYLCV showed an increase in the accumulation of miR167 when compared with healthy control. Plants inoculated with PVX showed an increase in the level of miR167 though the increase was less than that caused by ACMV, CLCuMV and CbLCuV infections (Figure 2).

\section{- miR168}

Infection of $N$. benthamiana plants ACMV, CbLCuV, CLCuMV and TYLCV showed an increase in level of miR168 when compared with healthy plants. Infection of PVX also resulted in increased accumulation of miR167 which was comparable with ACMV and CLCuMV infections. A significant increase was observed for CbLCuV and TYLCV infections (Figure 2).

\section{-miR 169 and miR170}

Infection of ACMV does not alter the level of miR169 significantly in $N$. benthamiana plants however, a slight decrease was observed when compared with healthy control plants (Figure 2). A slight increase in miR169 was observed in case of the infection of CLCuMV, CbLCuV and TYLCV (Figure 2). PVX infection in $N$. benthamiana also resulted in an increase in level of miR169 (Figure 2). A heat diagram summarizing the miRNA profiles in response to infection with the selected begomoviruses is given in Figure 3.

\section{Discussion}

Recent studies of both animal and plant viruses have shown that viruses alter the RNA silencing pathway to regulate host gene expression $[35,36]$. One of the limitations at present is that the mechanisms controlling such activities are unclear. However, a generally accepted concept is that RNA silencing is a natural defense response of plants against invading viruses. To counter RNA silencing viruses encode certain proteins that can block the RNAi pathway and are referred to as suppressor of gene silencing [36,37]. It has been demonstrated that viral suppressors of RNA silencing can interact/ interfere with the miRNA pathway [30,31], although it remains unclear whether these interactions are the part of the survival strategy of viruses or just side effects (collateral damage) of their infection cycle. In the work presented here the interaction begomoviruses ACMV, CLCUMV and its associated CLCuMB, TYLCV and $\mathrm{CbLCuV}$ with selected host miRNAs was studied. With

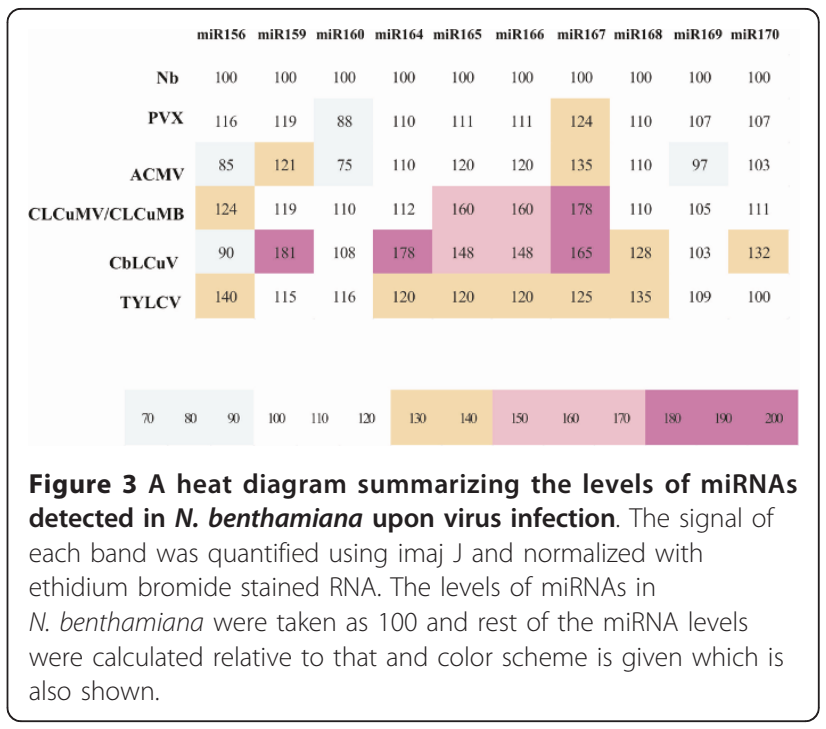

the exception of $\mathrm{CbLCuV}$, these viruses are well characterized as far as suppressors of gene silencing are concerned. TrAP and AC4 encoded by ACMV [32], the V2 protein encoded by TYLCV [38], the TrAP, C4 and V2 proteins of CLCuMV and $\beta C 1$ encoded CLCuMB have been shown to have suppressor of gene silencing activity (Amin et al., manuscript in preparation).

miR156 has been shown to act on SQUAMOSA PROMOTER BINDING PROTEIN (SPL), which is believed to be a transcription factor $[39,40]$. The accumulation of miR156 upon infection by selected begomovirus showed that these viruses can be divided into two groups. Infections by the bipartite viruses (ACMV and CbLCuV) lead to a decrease in miR156 while infections by the monopartite viruses (CLCUMV and TYLCV) lead to an increase. It has been shown that SPL3 is a target of miR156 and constitutive expression of miR156 results in a prolonged juvenile vegetative phase and delayed flowering [40].

miR159 was identified independently by two groups $[8,41]$ and is thought to target mRNAs coding for MYB proteins which are known to bind to the promoter of the floral meristem identity gene LEAFY (LFY; [9]). The LFY genes play an important role during the transition from the vegetative to the reproductive phase, as it is both necessary and sufficient for the initiation of individual flowers [42]. LFY is extensively expressed during the vegetative phase of plant growth [43]. Thus, the reduction in the expression of the LFY gene plays an important role in the transition from the vegetative phase to the sexual phase. A uniform pattern of up-regulation was observed for the accumulation of miR159 as a result of the infection of begomoviruses. These findings are in line with the recent findings where it was shown that upon infection of Tomato leaf curl New 
Delhi virus (ToLCNDV) the level of miR159 was increased. In the same studies it was also shown that the symptom development may also be due to the upregulation of this miRNA [44].

TYLCV REn interacts with at least two host-encoded proteins, PCNA and the RBR that play an important role in altering the cell cycle [45]. A major function of RBR proteins is to control the expression of many genes required for cell cycle progression, by regulating the activity of E2F transcription factors [46]. The study here has shown a further way that REn may influence the cell-cycle of the host, by up-regulating miR159. CbLCuV has been shown to alter expression of cell cycle-associated genes, preferentially activating genes expressed during the $\mathrm{S}$ and $\mathrm{G} 2$ phases as well as inhibiting genes active in $\mathrm{G} 1$ and $M$ phases. A limited set of core cell cycle genes associated with cell cycle reentry, late $\mathrm{G} 1, \mathrm{~S}$, and early G2 had increased RNA levels, while core cell cycle genes linked to early G1 and late G2 had reduced transcripts [47].

miR160 is encoded on chromosome 2 in Arabidopsis [8] and targets mRNAs coding for auxin response factor (ARF) proteins $[9,31]$. ARFs are a major class of transcription activators and repressors that facilitate the auxin signal by binding to specific cis-elements in the upstream regions of auxin-inducible genes [48]. The study presented here has shown a basic difference in the infection patterns of OW bipartite and monopartite viruses. ACMV infection resulted in decreased accumulation of miR159, whereas for the OW monopartite virus infection resulted in the increased accumulation of miR160. The major role in these interaction could be of $\beta C 1$ in case CLCuMV/CLCuMB and TrAP/V2 of TYLCV because the phenotypes produced by $\mathrm{V} 2$ of TYLCV and $\beta C 1$, when expressed from the PVX vector in $N$. benthamiana, produced virus-like symptoms $[49,50]$. These symptoms suggest that the auxin response has been disturbed. The finding that CLCuMV/CLCuMB, TYLCV and CbLCuV infections of $N$. benthamiana resulted in an increase in the levels of miR160 also suggest a general behavior of begomoviruses infection in reducing the response to auxin in infected plants, although this was not the case for ACMV. This suggestion will need further experimental confirmation. Earlier studies with the Curtovirus BCTV showed that infection reduces auxin levels, but the authors were unable to show a correlation between reduced auxin and visible symptoms [51].

The miRNA miR164 negatively regulates several genes that encode NAC-like transcription factors $[7,31,52,53]$. These genes include CUP-SHAPED COTYLEDON 1 (CUC1) and $\mathrm{CUC2}$, which are expressed in, and are necessary for, the formation of boundaries between meristems and emerging organ primordia [54-56]. Failure to establish organ boundaries leads to severe developmental consequences [57]. Infections of all four begomoviruses resulted in an increased accumulation of miR164, suggesting that the viruses down regulate the NAC-like transcription factors. This effect upon miR164 may be one of the contributing factors to the induction of disease symptoms for these viruses. We have observed that with the exception of CLCuMV, there is a significant increase in the levels of miR164 upon PVXmediated expression of the TrAP genes of all viruses under study (Amin et al, unpublished data). Therefore, TrAP might be the gene responsible for this interaction of viruses with miR164. It has been shown that the TrAPs of ToLCNDV, Papaya leaf curl virus (PaLCuV) and CLCuKoV can counter a HR induced by NSP (ToLCNDV) or V2 (PaLCuV and CLCuKoV $[58,59]$. Virus up-regulation of miR164 may provide a possible explanation of this phenomenon. A recent study has shown that oxygen responsive elements 1 (ORE1), which is a NAC-like transcription factor, positively regulates aging-induced cell death in Arabidopsis thaliana leaves. ORE1 expression is up-regulated concurrently with leaf aging by ethylene insensitive 2 (EIN2) but is negatively regulated by miR164. miR164 expression gradually decreases with aging through negative regulation by EIN2, which leads to the up-regulation of ORE1 expression [60] and thus to the cell death. Up-regulation of miR164 thus will counter the cell death, and thus possibly also HR associated cell death due to NSP and V2.

A uniform pattern of up-regulation was observed with relation to the accumulation of miRNA165/166. miR165 is found on chromosome 1 in Arabidopsis and regulates HD-ZIPIII transcription factor genes, PHABULOSA (PHB) and PHAVOLUTA (PHV; [9]). It has been shown in Arabidopsis that the establishment of leaf polarity requires the generation and perception of positional information along the radial axis of the plant [61]. The results presented here also showed that in general, begomovirus infection resulted in increased accumulation of miR165/166. The genes which upon inoculation produced virus like symptoms may be involved in this interaction. It has been earlier reports that transgenic Arabidopsis expressing the TYLCCNB $\beta C 1$ exhibited virus-like symptoms. These morphological changes were paralleled by a reduction in miR165/166 levels and an increase in PHB and PHV transcript levels. Two factors, ASYMMETRIC LEAVES 1 (AS1) and ASYMMETRIC LEAVES 2 (AS2), are known to regulate leaf development as an AS1/AS2 complex [62]. $\beta C 1$ is able to partially complement as 2 mutation. We also observed significant decrease in the levels of miR165/166 upon PVX-mediated expression of CLCuMB $\beta C 1$ (Amin et al., unpublished data), CLCuMV/CLCuMB infection led to an increased accumulation. 
The results show that begomovirus infection generally increases the accumulation of miR167. It has been shown that miR167 targets ARF 6 and ARF8 $[9,63]$. ARF proteins regulate embryogenesis, root development and floral organ formation [63-67]. ARF6 and ARF8 regulate flower maturation [68]. Infection of plants with some begomoviruses, as well as constitutive expression of some of their genes in plants results in severe developmental defects. For example, transgenic expression of ACMV AC4 in Arabidopsis resulted in stunted plants with severe developmental defects, such as narrow rosette leaves and lack of development of reproductive tissue [33]. Similarly the transgenic expression of $\beta C 1$ in $N$. benthamiana as well as expression on $\beta C 1$ from PVX resulted in severely twisted plants $[49,69,70]$. Thus, the results presented here suggest a possible mechanism for the induction of these virus-like symptoms.

With the exception of $\mathrm{CbLCuV}$, infection of $N$. benthamiana plants with all viruses under study resulted in a slightly increased accumulation in the levels of both miR169 and miR170 which suggests that begomovirus infection does not significantly affect the levels of these miRNAs. It has been shown that miR169 and related miRNAs are strongly dependent on $\mathrm{P}$ or $\mathrm{N}$ status in Arabidopsis and rapeseed (Brassica napus) phloem sap, flagging them as candidate systemic signaling molecules [71].

The study presented here has shown that, in general, begomovirus infection (assuming that the four viruses originating from distinct classes of begomoviruses [NW, OW, bipartite, monopartite and betasatellite requiring] are representative) increases the accumulation of miRNAs. This finding is in agreement with an earlier study of RNA viruses from three distinct families (Tobamoviridae, Potyviridae, and Potexviridae) that examined a similar range of miRNAs [34]. However, it is difficult to reconcile the presence for all these viruses (both the begomoviruses and the RNA viruses) of proteins that apparently bind (and presumably inactivate/down-regulate) miRNAs with a system that ultimately leads to miRNA up-regulation.

\section{Methods}

Virus Infections

Agroinoculable infectious clones of begomovirus isolates CLCuMV-His[PK:Mul] (AJ496461), ACMV-[CM:DO3:98] (DNA-A, AY211885; DNA-B, AF112353), CbLCuV[US:Flo:96] (DNA-A, U65529; DNA-B, U65530) and TYLCV-Mld[ES:72:97] (AF071228) were used to infect $N$. benthamiana plants. Three leaves per plants were inoculated. Samples were collected at $21 \mathrm{dpi}$. The whole experiment was done on two independent biological replicates.

\section{miRNA Analysis}

Total RNA was isolated from leaves using TRIzol reagent (Invitrogen, Carlsbad, CA), 1/5 volume of $5 \times$ RNA loading dye (95\% deionized formamide, $0.025 \%$ bromophenol blue, 0.025\%Xylene cyanol FF, $5 \mathrm{mM}$ EDTA (pH8), $0.025 \%$ formaldehyde; $20 \mu \mathrm{l}$ of $10 \mathrm{mg} / \mathrm{ml}$ ethidium bromide was added per $2 \mathrm{ml}$ of dye) was added to $30 \mu \mathrm{g}$ of total RNA. After heating that at $65^{\circ} \mathrm{C}$ for $5 \mathrm{~min}$, sample was placed on ice for $2 \mathrm{~min}$ before loading it to TBE gel (15\%TBE; $7 \mathrm{M}$ urea). Gel was run in $1 \times$ TBE buffer at 150-180 volts for 2 to 2.5 hours. After removing gel from the cassette it was photographed under UV trans-illumination and details of the samples were documented.

RNA was transferred to Hybond $\mathrm{N}+$ (Amersham) by a semi-dry blotting system (Bio-Rad) at 10-12 volts for 45-60 min. The membrane was air dried, UV crosslinked and stored at $4{ }^{\circ} \mathrm{C}$ between two sheets of wet Whatman filter paper.

Oligonucleotide primers complementary to Arabidopsis miRNAs (miR156, miR159, miR160, miR164, miR165, miR166, miR167, miR168, miR169 and miR170) were end-labeled using a DIG olig-labeling kit according to manufacturer instructions (Roche, USA). The sequences of oligo-nucleotides used for end labeling are listed in Table 1. Blot was hybridized with probe at $42^{\circ} \mathrm{C}$ for 12-16 hours. Washing was done with 2XSSC, 1\% SDS and $1 \times$ SSC, $0.1 \%$ SDS for $30 \mathrm{~min}$ each. The blot was developed by using the CDP-Star method according to the manufacturer instruction (Roche) and image was taken on X-ray film (hyper film, Amersham, UK).

The intensity of bands was quantified by using software ImageJ. Data from these analyses were used to normalize the intensity of each band, based on rRNA loaded in each well. For virus infection the values for the miRNA species in non-infected $N$. benthamiana plants were set at 1 and other data calculated relative to this value. The data shown in Figure 2 is the average of

Table 1 Name and sequence of oligonucletides used for end labeling

\begin{tabular}{|c|c|}
\hline miRNA & Sequence \\
\hline miR156 & 5'-TGACAGAAGAGAGTGAGCAC-3' \\
\hline $\operatorname{miR} 159$ & 5'-TाTGGATTGAAGGGAGCTCTA-3' \\
\hline $\operatorname{miR} 160$ & 5'-TGCCTGGCTCCCTGTATGCCA-3' \\
\hline $\operatorname{miR} 164$ & 5'-TGGAGAAGCAGGGCACGTGCA-3' \\
\hline miR165 & 5'-TCGGACCAGGCTTCATCCCCC-3' \\
\hline miR166 & 5'-TCGGACCAGGCTTCATTCCCC-3' \\
\hline $\operatorname{miR} 167$ & 5'-TGAAGCTGCCAGCATGATCTA-3' \\
\hline miR168 & 5'-TCGCTTGGTGCAGGTCGGGAA-3' \\
\hline $\operatorname{miR} 169$ & 5'-CAGCCAAGGATGACTTGCCGA-3' \\
\hline $\operatorname{miR} 170$ & 5'-TGATTGAGCCGTGTCAATATC-3' \\
\hline
\end{tabular}


two independent biological replicates along with standard deviation (SD).

\section{Experimental design}

A group of $15 \mathrm{~N}$. benthamiana plants were agro-infiltrated with infectious clones of ACMV, CLCuMV/ CLCuMB, CbLCuV and TYLCV in two independent experiments. Potato virus X (PVX) was used as reference for virus infection with an RNA genome. All plants were kept in the same green house for duration of each experiment.

\section{Acknowledgements}

RWB is supported by the Higher Education Commission (HEC), Government of Pakistan, under the 'Foreign Faculty Hiring Program'. Funding for the work came from a grant under the Pak-US Linkage Scheme. The authors are grateful for the support of NIBGE and ILTAB (DDPSC) in conducting this study.

\section{Author details}

${ }^{1}$ Agricultural Biotechnology Division, National Institute for Biotechnology and Genetic Engineering (NIBGE), P O Box 577, Jhang Road, Faisalabad, Pakistan, ILTAB, Donald. ²Donald Danforth Plant Science Center, St. Louis, MO 63132, USA

\section{Authors' contributions}

IA, BP performed the experiments. IA, RWB, SM and CMF conceived the study and wrote the manuscript. All authors read and approved the final manuscript.

\section{Competing interests}

The authors declare that they have no competing interests.

Received: 4 January 2011 Accepted: 29 March 2011

Published: 29 March 2011

\section{References}

1. Bartel DP: MicroRNAs: Genomics, biogenesis, mechanism, and function. Cell 2004, 116:281-297.

2. Voinnet O: Origin, biogenesis, and activity of plant microRNAs. Cell 2009, 136:669-687.

3. Lee RC, Feinbaum RL, Ambros V: The C. elegans heterochronic gene lin-4 encodes small RNAs with antisense complementarity to lin-14. Cell 1993, 75:843-854.

4. Pasquinelli $A E$, Ruvkun G: Control and developmental timing by microRNAs and their targets. Annu Rev Cell Dev Biol 2002, 18:495-513.

5. Llave C, Kasschau KD, Rector MA, Carrington JC: Endogenous and silencing-associated small RNAs in plants. Plant Cell 2002, 14:1605-1619.

6. Mette MF, Kanno T, Aufsatz W, Jakowitsch J, van der Winden J, Matzke MA, Matzke AJM: Endogenous viral sequences and their potential contribution to heritable virus resistance in plants. EMBO J 2002, 21:461-469.

7. Park W, Li J, Song R, Messing J, Chen X: CARPEL FACTORY, a Dicer homolog, and HEN1, a novel protein, act in microRNA metabolism in Arabidopsis thaliana. Curr Biol 2002, 12:1484-1495.

8. Reinhart BJ, Weinstein EG, Rhoades MW, Bartel B, Bartel DP: MicroRNAs in plants. Genes Dev 2002, 16:1616-1626.

9. Rhoades M, Reinhart B, Lim L, Burge C, Bartel B, Bartel DP: Prediction of plant microRNA targets. Cell 2002, 110:513-520.

10. Llave C, Xie Z, Kasschau KD, Carrington JC: Cleavage of Scarecrow-like mRNA targets directed by a class of Arabidopsis miRNA. Science 2002, 297:2053-2056.

11. Tang G, Reinhart BJ, Bartel DP, Zamore PD: A biochemical framework for RNA silencing in plants. Genes Dev 2003, 17:49-63.

12. Baumberger N, Baulcombe DC: Arabidopsis ARGONAUTE1 is an RNA slicer that selectively recruits microRNAs and short interfering RNAs. Proc Natl Acad Sci USA 2005, 102:11928-11933.
13. Qi Y, Denli AM, Hannon GJ: Biochemical specialization within Arabidopsis RNA silencing pathways. Mol Cell 2005, 19:421-428.

14. Aukerman MJ, Sakai H: Regulation of flowering time and floral organ identity by a microRNA and its APETALA2-like target genes. Plant Cell 2003, 15:2730-2741.

15. Schwab R, Palatnik JF, Riester M, Schommer C, Schmid M, Weigel D: Specific effects of microRNAs on the plant transcriptome. Dev Cell 2005, 8:517-527

16. Arteaga-Vazquez M, Caballero-Perez J, Vielle-Calzada JP: A family of microRNAs present in plants and animals. Plant Cell 2006, 18:3355-3369.

17. Gandikota M, Birkenbihl RP, Hohmann S, Cardon GH, Saedler H, Huijser P: The miRNA156/157 recognition element in the 3' UTR of the Arabidopsis SBP box gene SPL3 prevents early flowering by translational inhibition in seedlings. Plant J 2007, 49:683-693.

18. Hanley-Bowdoin L, Settlage SB, Orozco BM, Nagar S, Robertson D: Geminviruses: models for plant DNA replication, transcription, and cell cycle regulation. Crit Rev Plant Sci 1999, 18:71-106.

19. Stanley J, Bisaro DM, Briddon RW, Brown JK, Fauquet CM, Harrison BD, Rybicki EP, Stenger DC: Geminiviridae. In Virus Taxonomy, VIIlth Report of the ICTV. Edited by: Fauquet CM, Mayo MA, Maniloff J, Desselberger U, Ball LA. London: Elsevier/Academic Press; 2005:301-326.

20. Varma A, Malathi VG: Emerging geminivirus problems: A serious threat to crop production. Ann Appl Biol 2003, 142:145-164

21. Mansoor S, Briddon RW, Zafar Y, Stanley J: Geminivirus disease complexes: an emerging threat. Trends Plant Sci 2003, 8:128-134.

22. Nawaz-ul-Rehman MS, Fauquet CM: Evolution of geminiviruses and their satellites. FEBS Lett 2009, 583:1825-1832.

23. Dry I, Krake LR, Rigden JE, Rezaian MA: A novel subviral agent associated with a geminivirus: the first report of a DNA satellite. Proc Natl Acad Sci, USA 1997, 94:7088--7093.

24. Zaitlin M, Hull R: Plant Virus-Host Interaction. Annu Rev Plant Physio 1987 38:291-315.

25. Finnegan EJ, Matzke MA: The small RNA world. J Cell Sci 2003, 116:4689-4693

26. Voinnet O: Non-cell autonomous RNA silencing: insights from viral infections. FEBS Lett 2005, 579:5858.

27. Dunoyer $P$, Voinnet $O$ : The complex interplay between plant viruses and host RNA-silencing pathways. Curr Opin Plant Biol 2005, 8:415.

28. Pfeffer S, Voinnet O: Viruses, microRNAs and cancer. Oncogene 2006, 25:6211-6219.

29. Roth BM, Pruss GJ, Vance VB: Plant viral suppressors of RNA silencing Virus Res 2004, 102:97-108.

30. Chapman EJ, Prokhnevsky Al, Gopinath K, Dolja W, Carrington JC: Viral RNA silencing suppressors inhibit the microRNA pathway at an intermediate step. Genes Dev 2004, 18:1179-1186.

31. Kasschau KD, Xie Z, Allen E, Llave C, Chapman EJ, Krizan KA, Carrington JC: P1/HC-Pro, a viral suppressor of RNA silencing, interferes with Arabidopsis development and miRNA function. Dev Cell 2003, 4:205-217.

32. Vanitharani $R$, Chellappan P, Pita JS, Fauquet CM: Differential roles of AC2 and AC4 of cassava geminiviruses in mediating synergism and suppression of posttranscriptional gene silencing. J Virol 2004, 78:9487-9498.

33. Chellappan P, Vanitharani R, Fauquet CM: MicroRNA-binding viral protein interferes with Arabidopsis development. Proc Natl Acad Sci USA 2005, 102:10381-10386

34. Bazzini AA, Hopp HE, Beachy RN, Asurmendi S: Infection and coaccumulation of tobacco mosaic virus proteins alter microRNA levels, correlating with symptom and plant development. Proc Natl Acad Sci USA 2007, 104:12157-12162.

35. Baulcombe D: RNA silencing. Trends Biochem Sci 2005, 30:290-293.

36. Voinnet $O$ : Induction and suppression of RNA silencing: insights from viral infections. Nature Genet 2005, 6:206-221.

37. Voinnet O: RNA silencing as a plant immune system against viruses. Trends Genet 2001, 17:449-459.

38. Zrachya A, Glick E, Levy Y, Arazi T, Citovsky V, Gafni Y: Suppressor of RNA silencing encoded by Tomato yellow leaf curl virus-Israel. Virology 2007, 358:159-165

39. Riechmann JL, Heard J, Martin G, Reuber L, Jiang C, Keddie J, Adam L, Pineda O, Ratcliffe OJ, Samaha RR: Arabidopsis transcription factors: genome-wide comparative analysis among eukaryotes. Science 2000, 290:2105-2110. 
40. Wu G, Poethig RS: Temporal regulation of shoot development in Arabidopsis thaliana by miR156 and its target SPL3. Development 2006, 133:3539-3547.

41. Mette MF, van der Winden J, Matzke M, Matzke AJ: Short RNAs can identify new candidate transposable element families in Arabidopsis. Plant Physiol 2002, 130:6-9.

42. Parcy F, Bomblies K, Weigel D: Interaction of LEAFY, AGAMOUS and TERMINAL FLOWER1 in maintaining floral meristem identity in Arabidopsis. Development 2002, 129:2519-2527.

43. Blazquez MA, Soowal LN, Lee I, Weigel D: LEAFY expression and flower initiation in Arabidopsis. Development 1997, 124:3835-3844

44. Naqvi AR, Haq QM, Mukherjee SK: MicroRNA profiling of Tomato leaf curl New Delhi virus (ToLCNDV) infected tomato leaves indicates that deregulation of mir159/319 and mir172 might be linked with leaf curl disease. Virol J 2010, 7:281

45. Settlage SB, See RG, Hanley-Bowdoin L: Geminivirus C3 protein: replication enhancement and protein interactions. J Virol 2005, 79:9885-9895.

46. Sabelli PA, Larkins BA: Regulation and function of retinoblastoma-related plant genes. Plant Sci 2009, 177:540-548.

47. Ascencio-lbanez JT, Sozzani R, Lee TJ, Chu TM, Wolfinger RD, Cella R, Hanley-Bowdoin L: Global analysis of Arabidopsis gene expression uncovers a complex array of changes impacting pathogen response and cell cycle during geminivirus infection. Plant Physiol 2008, 148:436-454.

48. Guilfoyle TJ, Hagen G: Auxin response factors. J Plant Growth Regul 2001, 10:281-291.

49. Qazi J, Amin I, Mansoor S, lqbal MJ, Briddon RW: Contribution of the satellite encoded gene $\beta C 1$ to cotton leaf curl disease symptoms. Virus Res 2007, 128:135-139.

50. Selth LA, Randles JW, Rezaian MA: Host responses to transient expression of individual genes encoded by Tomato leaf curl virus. Mol Plant Microbe In 2004, 17:27-33.

51. Smith SH, McCall SR, Harris JH: Alterations in the auxin levels of resistant and susceptible hosts induced by curly top virus. Phytopathology 1968, 58:1669-1670.

52. Baker CC, Sieber P, Wellmer F, Meyerowitz EM: The early extra petals1 mutant uncovers a role for microRNA miR164c in regulating petal number in Arabidopsis. Curr Biol 2005, 15:303-315.

53. Guo HS, Xie Q, Fei JF, Chua NH: MicroRNA directs mRNA cleavage of the transcription factor NAC1 to downregulate auxin signals for Arabidopsis lateral root development. Plant Cell 2005, 17:1376-1386.

54. Aida M, Ishida T, Tasaka M: Shoot apical meristem and cotyledon formation during Arabidopsis embryogenesis: interaction among the CUP-SHAPED COTYLEDON and SHOOT MERISTEMLESS genes. Development 1999, 126:1563-1570.

55. Heisler MG, Ohno C, Das P, Sieber P, Reddy GV, Long JA, Meyerowitz EM: Patterns of auxin transport and gene expression during primordium development revealed by live imaging of the Arabidopsis inflorescence meristem. Curr Biol 2005, 15:1899-1911.

56. Takada S, Hibara K, Ishida T, Tasaka M: The CUP-SHAPED COTYLEDON1 gene of Arabidopsis regulates shoot apical meristem formation. Development 2001, 128:1127-1135.

57. Aida M, Ishida T, Fukaki H, Fujisawa H, Tasaka M: Genes involved in organ separation in Arabidopsis: an analysis of the cup-shaped cotyledon mutant. Plant Cell 1997, 9:841-857.

58. Hussain M, Mansoor S, Iram S, Zafar Y, Briddon RW: The hypersensitive response to Tomato leaf curl New Delhi virus nuclear shuttle protein is inhibited by transcriptional activator protein. Mol Plant Microbe In 2007, 20:1581-1588

59. Mubin M, Amin I, Amrao L, Briddon RW, Mansoor S: The hypersensitive response induced by the V2 protein of a monopartite begomovirus is countered by the C2 protein. Mol Plant Pathol 2010, 11:245-254.

60. Kim JH, Woo HR, Kim J, Lim PO, Lee IC, Choi SH, Hwang D, Nam HG: Trifurcate feed-forward regulation of age-dependent cell death involving miR164 in Arabidopsis. Science 2009, 323:1053-1057.

61. Mallory AC, Reinhart BJ, Jones-Rhoades MW, Tang G, Zamore PD, Barton MK, Bartel DP: MicroRNA control of PHABULOSA in leaf development: importance of pairing to the microRNA $5^{\prime}$ region. $E M B O$ 2004, 23:3356-3364.

62. Xu L, Yang L, Pi L, Liu Q, Ling Q, Wang H, Poethig RS, Huang $\mathrm{H}$ : Genetic interaction between the AS1-AS2 and RDR6-SGS3-AGO7 pathways for leaf morphogenesis. Plant Cell Physiol 2006, 47:853-863.
63. Wang JW, Wang $L$, Mao YB, Cai WJ, Xue HW, Chen XY: Control of root cap formation by microRNA-targeted auxin response factors in Arabidopsis. Plant Cell 2005, 17:2204-2216.

64. Hardtke CS, Berleth T: The Arabidopsis gene MONOPTEROS encodes a transcription factor mediating embryo axis formation and vascular development. EMBO J 1998, 17:1405-1411.

65. Hardtke CS, Ckurshumova W, Vidaurre DP, Singh SA, Stamatiou G, Tiwari SB, Hagen G, Guilfoyle TJ, Berleth T: Overlapping and non-redundant functions of the Arabidopsis auxin response factors MONOPTEROS and NONPHOTOTROPIC HYPOCOTYL 4. Development 2004, 131:1089-1100.

66. Mallory AC, Bartel DP, Bartel B: MicroRNA-directed regulation of Arabidopsis AUXIN RESPONSE FACTOR17 is essential for proper development and modulates expression of early auxin response genes. Plant Cell 2005, 17:1360-1375.

67. Sessions A, Nemhauser JL, McColl A, Roe JL, Feldmann KA, Zambryski PC: ETTIN patterns the Arabidopsis floral meristem and reproductive organs. Development 1997, 124:4481-4491.

68. Nagpal P, Ellis CM, Weber H, Ploense SE, Barkawi LS, Guilfoyle TJ, Hagen G, Alonso JM, Cohen JD, Farmer EE, Ecker JR, Reed JW: Auxin response factors ARF6 and ARF8 promote jasmonic acid production and flower maturation. Development 2005, 132:4107-4118.

69. Saeed M, Behjatania SAA, Mansoor S, Zafar Y, Hasnain S, Rezaian MA: A Single complementrary-sense transcript of a geminiviral DNA $\beta$ satellite is determinant of pathogenicity. Mol Plant Microbe In 2005, 18:7-14.

70. Saunders K, Norman A, Gucciardo S, Stanley J: The DNA $\beta$ satellite component associated with ageratum yellow vein disease encodes an essential pathogenicity protein ( $\beta C 1$ ). Virology 2004, 324:37-47.

71. Pant BD, Musialak-Lange M, Nuc P, May P, Buhtz A, Kehr J, Walther D, Scheible WR: Identification of nutrient-responsive Arabidopsis and rapeseed microRNAs by comprehensive real-time polymerase chain reaction profiling and small RNA sequencing. Plant Physiol 2009, 150:1541-1555.

\section{doi:10.1186/1743-422X-8-143}

Cite this article as: Amin et al:: A common set of developmental miRNAs are upregulated in Nicotiana benthamiana by diverse begomoviruses. Virology Journal 2011 8:143.

\section{Submit your next manuscript to BioMed Central and take full advantage of:}

- Convenient online submission

- Thorough peer review

- No space constraints or color figure charges

- Immediate publication on acceptance

- Inclusion in PubMed, CAS, Scopus and Google Scholar

- Research which is freely available for redistribution 